\title{
The contribution of the reemergence of local identities to the achievement of the European socio-economic cohesion
}

\author{
Athanassios Gouridis ${ }^{1 *}$ \\ Director of the Technical Service of the Municipality of Soufli, Greece
}

\begin{abstract}
The present paper attempts to approach the recent phenomenon of the reemergence of the local identities in Europe, applying it, as a casestudy, on the European-border Greek-Thracian region in relationship with its Bulgarian neighbors. Globalization provoked fears in local communities for instability, dissolution and loss of identity, urging reactions, targeting to consistency, tranquility and security, traced particularly in the reappearance of local identification procedures. Nevertheless, the new approach, opposite to introversive, often connected to heterophobe behaviors, is actively positive and creative, functioning in the frames set by the EU. The identitybuilding capacities are now built from the inside, enriched by their interdependent character and visualized through sustainable synergies on a horizontal, cross-border, trans-regional, or trans-national level and a vertical one, functioning on various fields, such as culture, tourism, education, social inclusion, youth and training. The new procedures play a crucial role in the planning and implementation of the European policies, which now embrace communities, since it has been realized that local identities beyond a desirable, constitute an indispensable actor for the overall longevity, so that local diversity potentially contributes substantially to the European economic, social and territorial cohesion and integration.
\end{abstract}

\section{Introduction: the local identities}

The local identities issue is a strange and ambiguous one, potentially meaning too much or too little [1]. If we accept the definition for identity as the subjective appreciation of all respective to an object cultures, then local identity should refer to natural and cultural, in their wider senses, features, associated with certain "bounded", or open, "thin" or "thick", smallscaled spaces, defined by their local, spatial data [2-5].

For centuries local identities had been a matter of scholar, social, psychological or political involvement. Nevertheless, they started to attract attention as the subject of numerous studies and practices during the 1920s and 1930s, in the mid-war period, both in the North America and Europe; then, they were occasionally connected to extreme political and social movements $[1,3]$.

\footnotetext{
*Corresponding author: gouridis@0890.syzefxis.gov.gr, nasco t@@abv.bg
} 
The Second World War added the parameters of the wide redistribution of power and land, as well as the reappreciation of the principles and the previously universally established values and ideas. During the Cold War period new socio-psychological phenomena and political realities emerged, while new regimes and movements set their impact on the "identity" concept. The ethnic and racial upheavals of the late 1950s and the 1960s formed the ideal field for a more concrete, both theoretically and practically, approach, especially in the USA [1].

\section{Globalization and local identities}

Globalization could be, as well, considered as a very old historical phenomenon, witnessed, at least from the Hellenistic kingdoms and the Roman empire, to the English and the other colonial powers of the $19^{\text {th }}$ century AD. It was, nevertheless, the publication of the famous ten points of the "Washington consensus", set by the British economist John Williamson, in 1987, which marked the beginning of the new era. Only two years later, following the Fall of the Berlin Wall, the whole world became a witness of abyssal changes, where the old perceptions were shaken up from their grounds. Particularly, the Eastern Europe experienced the massive overthrow of the established system in the most painful way [4].

The frenzy invasion of the economic, cultural, socio-political and technological globalization since the early 90 s caused serious reactions. The removal of cross-border barriers in trade, banking system and political management, the striking interdependence of economic and cultural activities and the rapid predominance of the information technologies touched almost all the sectors of public and private life and smashed the traditional institutions, leaving the isolated, especially small, or weak, national, regional or local entities unprotected [4, 6-7]. Globalization, by turning the societies to "disorderly jungles", according to M. Castells, urged a fear of loss of identity, of uncertainty and a terror of being perished, or dissolved in an anonymous totality, an amorphous crowd, a crude amalgamation of local entities, or an impersonal, multinational company. Small, allegedly threatened communities looked for shelter in safe "places", often with the withdrawal to pre-merger organizations, which could offer sufficient protection from being harmed or even annihilated. The reaction to the eminent danger and, simultaneously, the pursuit of stability, security and tranquility led to the erection of "resistance" identity trenches against the enemies and the re-emergence of identification processes [7-8].

This reaction was mostly expressed as an "inward oriented" static, "historical" expression of subjectively perceived local identities, often deriving from ambiguous, loosely documented historical roots and the projection of the difference with the "other", first of all the neighbor, together with the supposed unbridgeable incompatibility of different local identities. This attitude occasionally led to the emergence of heterophobe, even racist phenomena and other extreme political expressions, while the concepts of democracy, tolerance and respect to the different were violently rejected [8-9].

\section{The new perception of the local identities}

Things around local expressions did not remain static; as a result of the emergence of political, economic, social and cultural new data, in a world characterized by diverse, deep interactions and relational complexity, multiplicity and fluidness, surrounded by an unstable political, social and ideological environment, intensely associated with mobility and networking, the previously accepted as eternal, fixed, unchangeable values and the hermetically "bounded" identities gradually started to be considered as mutable and flexible formulations of discourses $[3, .8,10]$. The first relevant theoretical formulations appeared in 
the mid-90s and were soon intensified, when an alternative way for a common political, economic and social administration was furnished by the European Union. The chronological succession can be traced on the reference of the steps of Bulgaria towards its accession in the European Union, which started in 1995 with the necessary application procedures, while its main phase was integrated in 2007, with the official entrance of the country.

After a short period of time the new concept of the local and regional identities entered catalytically the socio-economic and political parameters of public life. Identity-building capacities are now built from the inside, in a bottom-up procedure and they are largely formed by discourses, while wider, more complex values are attributed to identities. The latter continue to connote old meanings, though they are enriched with new traits, such as landscapes, dialects, toponyms, enterprises, quality of life etc. Moreover, they are largely perceived and constructed through their "collective", in a large extent, character, while they are visualized through sustainable synergies with other entities, on a horizontal, cross-border, trans-regional or trans-national level, as well as a vertical one, functioning together on interdependent fields, such as culture, tourism, education, health, social inclusion, youth, care for the elderly, green economy, environment and valorization of the areal geo-morphological or geo-strategic significance. In short, the expansion of globalization has led to the actualization, or even rebirth of local identities in a new, efficient form [3, 7, 10]. Identities and their formative discourses now are focused on cooperation with the other, the neighbor, revealing similarities and promoting shared interests with the outside world and, finally, stimulating local economic development, in an extroverted, dynamic manner. They are constantly shaped and reshaped by different actors, not hindering, but promoting local policies and interests. Thus, they comprise an approach to a new perception of estimating, transferring, discussing and reshaping its constituents. In this scheme, synergies and the interdisciplinary character form the basis for the new definition. Moreover, in this fluid, movable perception of local and regional identities, considerably formed through interviews, widely diffused oral culture also plays a crucial role, which derives from narratives, novels, poems, broadcast media, performances as well as plays, concerts, exhibitions etc. [1,8].

Constructed discourses are positively engaged in the process of negotiating, manipulating or affirming, corresponding to a certain demand, which co-acquires a wider political and economic meaning and importance and co-decides for the political map of an area, where political entrepreneurs find a field for the realization of their purposes and ambitions $[1,3,8]$.

In this reformulated political and social environment local identities are proved to be extrovertive and synergetic; consequently, they are used as a crucial instrument in the hands of the local administration and other stakeholders. They do not any more separate or differentiate from the "other", but, on the contrary, they connect for the benefit of all the participants, becoming, in a way, "communities" of discourses. They unite different places, attitudes and ways of watching the implementation of actions, the "other" and, finally, the actors themselves. Through the proper approach, interpretation and valorization of the local identities beyond their "bounded" limits transforms potentially local policies into effective vehicles, which head to a sustainable and integrated local development.

\section{The development profile of the area involved}

As far as it concerns the Central part of the Evros Regional Union and particularly the Municipality of Soufli a number of attached characteristics could be considered as decisive. Moreover, they could be as well partly ascribed to Greek and Bulgarian neighboring municipalities of the wider border area, largely indicating possible management of public resources though the valorization of local identities.

In short, the area presents a number of considerable strong points, up to now largely unexploited, for various reasons, which in short can be set as follows [11-12]: 
(a). It is a border region, almost uniquely for a Municipality placed between, not two other municipalities, but between two countries, Bulgaria and Turkey, the latter today being the eastern neighbor of the European Union. This "fate" is somehow expressed in a "thick", though widely accepted history buzzword: "we keep Thermopyles". Nevertheless, independently of the subjective national pride expressions, the region indeed possesses a crucial position, steadily growing geo-strategically.

(b) The area is located on the middle of the lower flow of the Evros-Maritsa River and on the vertical axis of the Egnatia road, which connects the Aegean Sea with the Corridor X, leading from the Central Europe, via Belgrade and Sofia to İstanbul and Asia.

(c) The Municipality presents a widely recognizable tourist identity, formed by the dipole of the famous protected by the Ramshar Convention and the 2000 Natura Agenda biotope of the National Park of Dadia-Levkimmi-Soufli and the uniquely remaining in Europe "town of silk", Soufli, with its activities and its "cocoon" architecture.

(d) Remarkable traditional elements and especially old, even pagan-origin customs are still preserved in the daily life of the rural settlements of the Municipality.

(e) The multilateral rural architectural physiognomy offers a number of important destinations, from the mountainous Pomak villages, to the traditional settlement of Levkimmi and the riverside historical villages.

(f) There is an impressive, unsaturated-unexploited potential of cultural and natural ecological destinations and almost unknown remarkable objects, such as the unique in extent, oldness and rarity fossil forest, the Megalithic culture, the old stone bridges etc.

(g) The abundance and variety of agricultural and forestry raw materials, disposed at a short, exploitable distance is combined with the widely known products of Soufli, such as silk, vine and cut meats.

(h) The multicultural physiognomy of the region engulfs harmonically different religious, linguistic and other cultural entities.

(i) The region guarantees safety and low crime rates, owed to a large extent to the presence of border military and police forces.

(k) Investment initiations and incentives, which support productive activities increase gradually, while the proximity of transport and communication infrastructures, such as airport, port etc. and the improvement of IT technologies are worthwhile.

(1) The participation of Bulgaria in the European Union offers wide challenges and opportunities.

On the other hand, a number of specific for the region, not negligible drawbacks could be referred in short. Indicatively we could mention:

(a) The reduction of the population, especially of youngsters, through internal migration, the lack of sufficient, quantitively and qualitatively, personnel, as well as the insufficient average vocational training in the tertiary sector.

(b) The border position of the area, often acting as a deterrent to medium and large-scale tourism investments, the substantial absence of an organized urban frame and of a high-level educational and research environment.

(c) The inertia, as part of a "thick" resistance perception, for the maintenance of the oldstructured agricultural character of the region against certain national and European policies and directives.

(d) The frustrating practical inequalities between regional municipalities of different size, due to national priorities and administrational arrangements, which overemphasize the role of the emerging urban centers, particularly Alexandroupolis, the capital of the Regional Union of Evros.

One should notice that many of the above-mentioned disadvantages are at the same time potential advantages, in terms of local development prospects. 


\section{Local administration in Greece}

Ten years ago, I had described here, in the 2nd Conference - Workshop of the Thracian University concerning the "Research on the cultural-historical heritage of the historicalgeographic region of Thrace", the efforts, undertaken locally, in the region of the Central Evros, mainly using co-financed, Operational, or Territorial Cooperation European programs, emphasizing on the fact that a correct estimation of results should require a longtime approach. Today, I daresay that, although in general terms things proceed satisfactorily, delays and problems remain, characterized by an incomprehensible, occasionally, sluggishness [13].

Problems are mainly structural and tactical. We could mention the lack of coordination between policy-decision makers; part of them, even today neglects to elaborate structures that could respond to the market and the public administration requisites, in order to be advantaged by strong local points. On the contrary, only narrow-mindedly, short-terms benefits are usually pursued. We could add the prolonged lack of personnel and training, obvious particularly in small-sized municipalities and similar entities, the lack of a persistent plan, the absence of the appropriate political civilization and of a coherent vision. Local Development Plans are laid out in abundance and they are renewed regularly, but they have almost never been taken seriously under consideration. Actions only recently are escorted by their promotion, popularization and, even more, branding of the material and immaterial outputs [13].

The accession of Greece in the European Union in 1981 had an ambiguous effect, raising on one hand hopes and on the other, simultaneously, provoking a fear of losing national, regional or local identities and certainties. Typical was the emergence of "pseudo-scientifictsalga" approaches, especially in history and social anthropology, as well as the deification of national successes in sports, such as weightlifting and football, or the Eurovision songcontest [9].

During the period 1997-2017, Greece underwent a triple administrative reform, with successive compulsory amalgamation procedures. The reaction of the local communities was rather hypotonic, despite the partial intense resistance outbursts. In fact, in a period of generosity, since the reforms almost coincided with the years of the main familiarization with the united European administrative and economic structures, levity prevailed and only a small minority of entities comprehended the new environment, confronting things seriously. The tiny Community and then Municipality of Tycheron, today a Municipal Unity of Soufli is still mentioned for the multiply award-winning, multilateral innovative interventions.

The second in thirteen years, further amalgamation of the Local entities in 2010, through the "Kallikratis" Law (no. 3852/2010), partly cancelled the previous administrative reformation of the "Kapodistrias" Law (no 2539/1997), since it was mainly an up-to-bottom administrative procedure, which did not take into account the needs and identities of the local populations. Moreover, it coincided with the outbreak of the Global Economic Crisis, which sank Greece into despair and set it in the position of the defendant for faults, barely apprehended by its wrongdoers. Panic found its expression in extreme political and cultural forms, drawn from the armory of "heavy" local and national identities. The crisis prevented the Greek local authorities from undertaking brave or even considerable steps, thus characterizing a period of reservation and retreat. Especially small municipalities, which did not afford to dispose with personnel, budget, or the political power, destined only for the large entities, were extremely difficult to keep in pace with the Community directives and the offered opportunities. Moreover, the new amalgamation grew the distance between the potential stakeholders and weakened internal procedures, connected to political participation and democracy [8]. 
At the same time, though, the imposed reforms provided the necessary legal frame, which transferred extended responsibilities and autonomy of action to the local authorities, encouraged vital competences and synergies and set to the receivers both the ability and the need for cooperation, although the central government did not always take care for the supply of the necessary financial means to cope with the new duties.

The whole scenery could be perhaps better comprehended with the reference to a peculiar attribute, expression of an inherent collective pathology, valid for both Greece and Bulgaria and still surviving in a part of intelligentsias and opinion makers of both countries [9]. It was an introverted ideological distortion, developed already in the garden of the 19th century Romantism and characterized by the resource to a bright past, in order to cover modern weaknesses. Unjustified, arrogant self-confidence, strangely mixed with a phenomenally opposite "raya" subconscious introversion, led to a sterile defensive tactical confrontation of the incoming challenges. Moreover, as far as it concerned the Greek side, the late incorporation of the "Western" Thrace into the national corpus (1920), the results of a disastrous civil war (1946-1949) and the migration flows of the 1960s-early 1970s largely contributed to the disintegration of the Northern Greek regions. Fortunately, the sad adventures of the two countries were succeeded by an early post-war conciliation and a constantly improving level of mutual understanding, leading to the so called "successful Balkan story", a bright practice in a turbulent Balkan peninsula [9]. This attractive new route is reflected on the recent trans-border cooperation, where extroversion, exhibited by the public and the private sector of both countries is focused on the valorization of the region and their values, as it is traced on the numerous coherent and realistic, multiplicative proposals and implemented projects, which cover impressively wide thematic fields.

\section{Good examples in the region of the Central Evros}

Applications, which valorized collective, cooperative, extrovertive local and regional identities were implemented through exemplary procedures of discourses, concerning local entities. It was mainly European Union initiatives and programs, which offered the opportunity to small unities, mainly municipalities, to valorize identities and advantages, especially some of those which were up to then forgotten by the central administration. Topics, such as environment, local architecture, traditional, tangible and intangible heritage, religious buildings and other special purpose constructions have been engulfed as the vocabulary and the official priorities of the various cooperating schemes.

The basic current instrument for the implementation of the local policies is the Corporate Pact for the Development Framework 2014-2020 (ESPA), with its sectoral and regional applications, which forms the main strategic plan for the development of the country, while the significant resources come from the Structural and Investment Funds of the European Union. The running programming period, 2014-2020, in force until 2023, aims, in a large extent to rectify the structural weaknesses of the country, contributing to the exit from the economic crisis, together with the confrontation of the created problems, economic and social. The Pact was also called to assist in achieving the national goals towards the "Europe 2020" Strategy, while it had incorporated the largest number of separate, minor programs or initiatives, such as the Leader initiative and then programme, which is now part of the Operational Plan of the Ministry of Agricultural Development and forms a useful instrument for the alternative development of the rural regions [14-15].

Nevertheless, the most important funding instrument for the border regions is the Interreg Programme, initially as well initiative, otherwise known as European Territorial Cooperation Programme (ETC). Interreg provides a powerful framework for joint actions and policy exchanges between national, regional, and local actors, as the basic vehicle for the implementation of one of the two European Union goals of cohesion policy, in order to 
promote its harmonious economic, social and territorial development. It is consisted of three strands of cooperation, cross-border (Interreg A), transnational (Interreg B) and interregional (Interreg C). The cross-border, Interreg A Greece-Bulgaria strand forms the most valuable factor in valorizing the collective identities of the relevant regions $[16,17]$.

Characteristic is a recent, inter-municipal cooperation between the Municipalities of Soufli and Haskovo. The project under the acronym "Fire Detection" had received the highest ranking of the environmental Interreg A Greece-Bulgaria 2014-2020 proposals. The project applies an innovative technology, concerning the environmental management, by installing optical and thermal cameras of observation, aiming to the protection of the biodiversity of the forests of Haskovo and the unique in significance, protected by the Ramshar Convention and the Natura 2000 Agenda, National Park of Dadia-Levkimmi-Soufli, extending on the fringes of the East Rhodopes Mountain massive, historically known as the Mountain of God [18].

An early Interreg for Greece, Leader for Bulgaria, double project, from the period when each partner kept its own plan, budget and funding instrument was "Architecture on the routes of silk" while the Bulgarian partner implemented a project dealing with the historical development of the sericulture as a traditional vocation in the trans-border regions. Through the project the Thraco-Bulgarian traditional architecture had been enabled to enter the Greek cognitive menu, while the unique, continuing experience of Soufli in sericulture and silk production was transferred to the Bulgarian border municipalities, once occupied with sericulture and silk production; both parts enjoyed an unprecedented "bona fide" cooperation, which continued successfully through the common projects that followed $[19,20]$.

The Interreg project under the acronym "Dimitrovgrad to ACCESS", implemented in the years 2012-2014, is an example of indirect, though constructive valorization of the local identities, since it was dealing with the road construction of a mountainous, isolated Pomak area, which lies exactly on the border with Bulgaria. The task was supplemented by similar infrastructure projects, financed mainly by the Regional Operational Co-Financed Programs (PEP-ESPA); they jointly enlightened hidden sides of vulnerable local groups, protecting and promoting the local natural resources and the cultural, unique tradition. At the same time, the Bulgarian partner, the Municipality of Dimitrovgrad, improved the access to the tourist destination of the Sanctuary of Nymphs, in Kasnakovo [17, 21].

The project "The past as future: historical topography of the area of Municipality of Soufli and Local Development" was comprised of five sub-projects, covering all the possible relevant spectrum, from the controversial field of the ancient Thracian history to the topographic surveys of archaeological sites and the promotion of the implemented work through numerous outputs and a closing Greek-Bulgarian Scientific Conference. The cooperation of municipal and other entities from Kardzali, Melnik, Yakoruda, Svilengrad and Madzarovo shared with the Greek archaeological science and management a different, alternative perspective of the Ancient Thracian history, contributing to the common transgression of long-standing superstitions and national ancyloses, an attitude, expressed perfectly by professor Ivan Marazov's heading of his presentation in the conference: "Orpheus without frontiers" [22].

We could add a considerable number of projects, focusing mainly on infrastructures, as well as on equipment and soft measures, which contributed to the valorization of local identities, such as the JOVAPROB project (Joint valorization and promotion of the old baths in the trans-border area), which dealt with the restoration and new use of the old Ottoman baths of Didymoteichon and Svilengrad, of the late 14th and early 16th century, respectively and potentially promoting the neglected touristically and scientifically topic of the Balkan Ottoman Architecture, the Old Stone Bridges restoration project, bearing, besides its practical meaning, a high symbolic one, as congenital to the basic principles of the Interreg 
Programme. In "LA-GRBG-ENERGYNET" three Bulgarian and four Greek border Municipalities established a thematic energy network, aiming to combine experience, knowledge and efforts for the improvement of the energy management in the involved transborder regions [23-25].

All the projects, besides their main activities held a considerable part for the implementation of soft measures, such as popularization and promotion of outputs, acquaintance with specific groups, such as pupils or elderly people and activities widening results into friendly and utterly useful objects. Moreover, besides the quantitative, directly countable data, equally important are indirect, qualitative activities, concerning mentalities, citizens' behavior, approach of vulnerable groups etc. Indicatively, we mention the Christmas thematic park-village of "Like a Fairy Tale", sheltered in the restored through successive cofinanced projects old silk factory of the Tzivre brothers at Soufli, a jewel of industrial archaeology, or the common educational activity "Cocoon Creative Lab" of the Interreg Balkan-Mediterranean and Greece-Bulgaria Managing Authorities which was implemented in Soufli, in 2018, implemented by little pupils from Svilengrad and Soufli in the Day of European Cooperation (ECDAY). The project was prepared and executed by students of the Faculty of Visual and Applied Arts of the Aristotle University of Thessaloniki, in order to promote through children, the idea of trans-border cooperation with the help of arts and silk [26-27].

\section{The European Union new prospects}

The working environment offered by the European Union was more than adequately hospitable up to now. The new frame set, as it is reflected on the basic axes of the new programming period 2021-2027 is even more promising. It is unfolded through only five, instead of the previous eleven targets-goals. The high qualitative, humane, citizen-oriented approach is evident at the goal no.4, through criteria, concerning social rights, qualitative employment and capacities, as well as equal access to health, while in no. 5 a vision for a "European Union closer to citizens" and their voice is deployed, where development strategies are compiled synthetically, evolving from a local level to a sustainable urban development all over the Union, through exhibiting specific care for trans-border regions. The new directions of the Interreg 2021-2027 emphasize the importance of tailored, placebase approaches, which will ensure that no places or citizens are left behind. They, as well, aim to a stronger cooperation across territorial boundaries and across sector policies with empowerment of the various actors involved, through integrated territorial, place-based strategies, all of them concretely implemented on the ground [16].

The comprehension of Europe's cultural diversity goes beyond solely the conservation and protection of tangible heritage and drives forward integration and social inclusion. The application of the axes for the states of the Union favors the new, creative, extroversive and holistic approach of local and regional identities, largely implemented through cooperative schemes, valorization of the local values and merits, apportioned through various funding instruments of the European Union, its Parliament and Commission, as well as the United Nations, or supported by the above mentioned entities or initiatives, such as Europe for Citizens, the Council of European Municipalities and Regions (CEMR), the United Nations Advisory Council of Local Authorities, the united Cities and Local Government, Agenda 21, Covenant of the mayors for climate and energy, while the community Legislature supports the whole frame [6].

The European Community expresses clearly that Cohesion, which was one of its primary goals, since its beginning, continues to be the first and indispensable characteristic, which should be pursued and promoted. This could be achieved by the active respect to those who are involved, a synthetic elaboration and the optimum valorization of their local values and 
identities. As it is reflected in the statements of the EC initiative "New Narratives for Europe", the new frame engulfs local identities, as culture, environment etc., through bottomup procedures, which play a vital role for shaping the European societies, in order to achieve truly inclusive, just and diverse ideas [5].

Thus, the new approach of the local identities forms not only a desirable, but an indispensable part of the planning and implementation of the European policies, as well, since local diversity contributes substantially to the European economic, social and territorial cohesion and integration. A strong Europe could not exist without a bottom-up decision procedure, a competent local and regional self-government, co-deciding with all policy stakeholders [6]. As the commissioner for Cohesion and Reforms, Elisa Ferreira has recently set: "Cohesion policy remains the beating policy of European solidarity...(but) ... we need now to fill it with content and prioritize the investments.... into real chance for our Member States, regional and local authorities, citizens and companies... (into) a spirit of citizenship" [28].

\section{References}

1. R. Brubaker, Fr. Cooper, Theory and society, 29(1), 1-47 (2000)

2. A. Taylor, Multiculturalism and the politics of recognition, (Princeton University Press, 1994)

3. A. Paasi, Reg. Stud., 47(8), 1206-1219 (2013)

4. St. Tartaglia, M. Rossi, Comm. Psych. Glob. Persp., 1(1), 105 - 121 (2015)

5. Agenda21.culture, [Online], https://www.agenda21.culture.net, [Accessed: June 2021]

6. M. Kohler, The Council of European Municipalities and Regions: shared governance in a world featured by globalization issues, in Open edition book: Globalization and the City, Universität Innsbruck, 207-217 (2013)

7. J. MacInnes, Br. J. Sociol., 57(4), 677-698 (2006)

8. K. Terlouw, Local Gov. Stud., 42(6), 938-957 (2016)

9. A. Gouridis, The Greek and the Bulgarian Thrace: is there place to work on together?, in Proceedings of Scientific Conference with International Participation "Muzeyno delo, prouchvaniya i inovatsii”, 4-5 October 2018, Harmanli, Bulgaria (2018)

10. A. Leete, Introduction: dynamic perspectives of identity politics, (2012), [Online], http://www.folklore.ee/ folklore/51 /introduction.pdf

11. A. Gouridis, Protasi chorotaxikou shediasmou Dimou Soufliou gia ton tourismo gia to etos 2021 (Proposal for the spatial planning of the Municipality of Soufli for tourism for the year 2021), Soufli, Greece (2020)

12. A. Gouridis, Epiheirisiako Programma Dimou Soufliou periodou, (Operational Programme of the Municipality of Soufli for the period 2014-2019, Soufli, Greece (2014)

13. A. Gouridis, TJS, 9(3), 120-130, (2011)

14. ESPA 2014-2020, https://espa.gr/en/pages/, [Accessed: June 2021]

15. European Commission, https://ec.europa.eu/eu 2020, [Accessed: June 2021]

16. Interreg Europe, https://www.interregeurope.eu, [Accessed: June 2021]

17. Interreg Greece-Bulgaria, https://www.greece-bulgaria.eu, [Accessed: June 2021]

18. Interreg Greece-Bulgaria Fire Detection Project, https://www.fire-detection.eu, [Accessed: June 2021] 
19. A. Gouridis, Buildings of silk: Architecture on the routes of silk, (Soufli, Greece, 2009)

20. A. Gouridis, Silk routes in the Byzantium and the Ottoman empire and the history of the town of Soufli, (Soufli, Greece, 2009)

21. Official website of Municipality of Dimitrovgrad, https://www.dimitrovgrad.bg/bg/pages, [Accessed: June 2021]

22. A. Gouridis, The past as future, in the context of INTERREG III Program "Historical Topography of the Area of the Municipality of Soufli and Local Development", Soufli, Greece (2009)

23. Jovaprob, https://www.facebook.com/jovaprob, [Accessed: June 2021]

24. A. Gouridis, Restoration and promotion of the old bridges of the Municipality of Soufli, (Greece, 2008)

25. Energy thematic network of cross-border Greek and Bulgarian local authorities (LAGRBG-ENERGYNET), https://www.up2europe.eu/projects/LA-GRBGENERGYNET, [Accessed: June 2021]

26. Official website of Municipality of Soufli, https://www.soufli.gr/index.php/el/component/search, [Accessed: June 2021]

27. Design Lab for Kids, https://www.designlabkids.org, [Accessed: June 2021]

28. European Commission, EU regional and urban development, https://ec.europa.eu/info/eu-regional-and-urban-development, [Accessed: June 2021] 